\title{
Involvement of a chromomycin ABC transporter system in secretion of a deacetylated precursor during chromomycin biosynthesis
}

\author{
Correspondence \\ Carmen Méndez \\ cmendezf@uniovi.es
}

Received 8 March 2007

Revised 17 May 2007

Accepted 4 June 2007

\author{
Nuria Menéndez, Alfredo F. Braña, José A. Salas and Carmen Méndez \\ Departamento de Biología Funcional e Instituto Universitario de Oncología del Principado de \\ Asturias (IUOPA), Universidad de Oviedo, Oviedo, Spain
}

\section{INTRODUCTION}

The aureolic acid group of antitumour agents comprises mithramycin, chromomycins, olivomycins, chromocyclomycin, UCH9 and durhamycin (Rohr et al., 1999). The agents inhibit growth and multiplication of several tumour cell lines, and they also act on Gram-positive bacteria. Some of the members of this family have clinical applications, and they are used for the treatment of certain tumours, such as disseminated embryonal cell carcinoma and Paget's bone disease, and also for the control of hypercalcaemia in patients with malignant diseases (Remers, 1979; Skarbek \& Speedie, 1981). More recently, chromomycin and mithramycin have been found to stimulate K562 cell erythroid differentiation (Bianchi et al., 1999), and both drugs have been suggested as potential neurological therapeutics (Chatterjee et al., 2001), and for use in the treatment of HIV-1 (Bianchi et al., 1997). The antitumour properties of these compounds are ascribed to their inhibitory effects on replication and transcription processes during macromolecular biosynthesis by interacting, in the presence of $\mathrm{Mg}^{2+}$, with

Abbreviations: ABC, ATP-binding cassette; DDACA3, 4A,4E-Odideacetyl-chromomycin $A_{3}$.
GC-rich nucleotide sequences located in the minor groove of DNA (Sastry \& Patel, 1993; Sastry et al., 1995; Barcelo et al., 2007).

Structurally, the aureolic acid compounds belong to the large and important family of the aromatic polyketides. All members of the group (with the exception of chromocyclomycin) consist of a tricyclic chromophore that has one or two aliphatic side chains (aglycone), and which is glycosylated at two different positions with saccharide chains of variable length. Mithramycin and chromomycin $\mathrm{A}_{3}$ (Fig. 1) share the same aglycone, and they differ only in some of the sugars attached to it (Wohlert et al., 1999). The gene clusters involved in the biosynthesis of mithramycin (Blanco et al., 1996, 2000; Fernández et al., 1998; Lozano et al., 2000; González et al., 2001; Lombó et al., 1996, 1997; Prado et al., 1999) and chromomycin $A_{3}$ have been cloned and characterized (Menéndez et al., 2004a, b, 2006). Interestingly, although there is high similarity between most individual mithramycin and chromomycin genes, the arrangement of genes in both clusters is organized in a substantially different way (Menéndez et al., 2004a). It has also been reported that the producer organisms of these two compounds, Streptomyces argillaceus ATCC 12956 (mithramycin producer) and Streptomyces griseus subsp. 


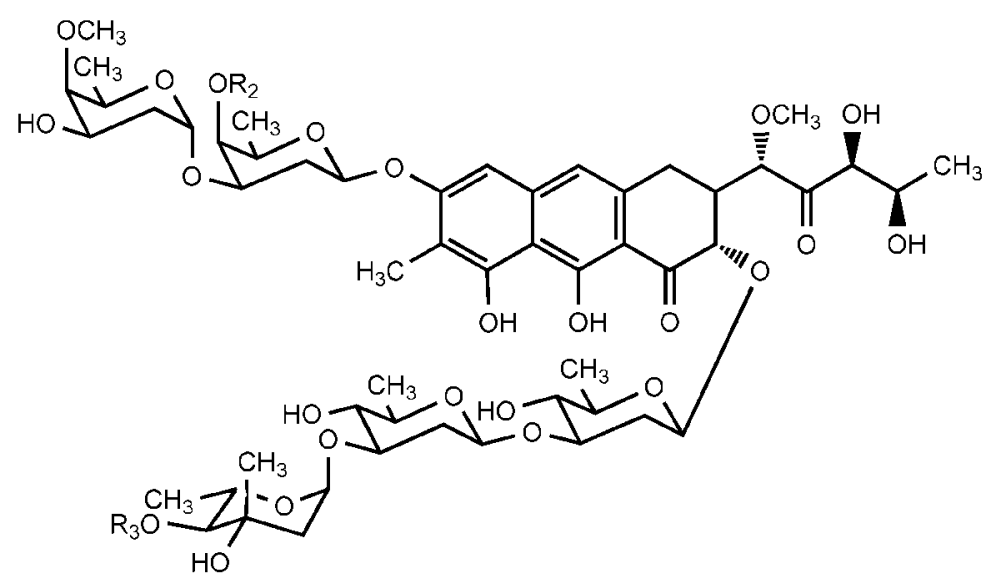

Chromomycin $\mathrm{A}_{3}: \mathrm{R}_{2}=\mathrm{R}_{3}=$ acetyl

DDACA3: $\mathrm{R}_{2}=\mathrm{R}_{3}=\mathrm{H}$

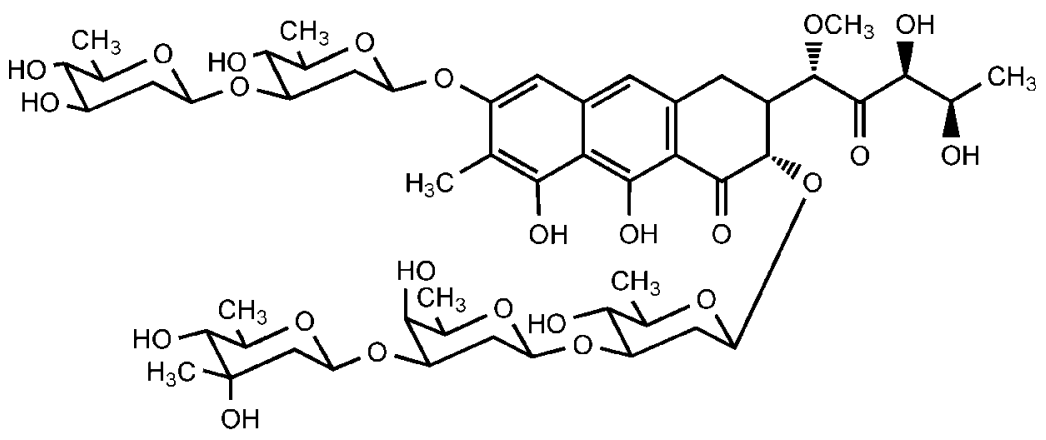

Mithramycin
Fig. 1. Chemical structures of mithramycin, chromomycin $\mathrm{A}_{3}$ and DDACA3. griseus ATCC 13273 (chromomycin $\mathrm{A}_{3}$ producer), are naturally highly resistant to their own produced antibiotic, but, despite the close structural similarity between these two drugs, they do not show cross-resistance (Fernández et al., 1996). In the mithramycin producer, the main resistant determinant is a type I ABC (ATP-binding cassette) transporter system (Méndez \& Salas, 2001) encoded by the $m \operatorname{tr} A$ and $m t r B$ genes; the system is able to confer high level of resistance to mithramycin, but not to chromomycin (Fernández et al., 1996). Analysis of the chromomycin gene cluster revealed, as a putative selfresistance mechanism, two genes encoding an ABC transporter system, and a gene encoding an UvrA-like protein of ABC excision nuclease systems that are responsible for DNA repair (Menéndez et al., 2004a).

Here, we report the characterization of the chromomycin$\mathrm{A}_{3}$-resistance determinants $\mathrm{CmrAB}$ and $\mathrm{CmrX}$. We propose a model for chromomycin secretion that involves the transport by the $\mathrm{CmrAB} A B C$ transporter of one of the last biosynthetic intermediates in chromomycin $\mathrm{A}_{3}$ biosynthesis, 4A,4E-O-dideacetyl-chromomycin $\mathrm{A}_{3}$ (DDACA3), and its subsequent acetylation by the membrane-bound acetyltransferase $\mathrm{CmmA}$, to finally render the fully active chromomycin $\mathrm{A}_{3}$. Implications of this secretion model in the biosynthesis and self-resistance to chromomycin in the producer organism are discussed.

\section{METHODS}

Micro-organisms, culture conditions and plasmids. S. griseus subsp. griseus ATCC 13273, a chromomycin $\mathrm{A}_{3}$ producer, was used as donor of chromosomal DNA, and for gene-disruption experiments. The mutant strain S. griseus C10A was used for production of DDACA3, as previously described (Menéndez et al., 2004b). For sporulation on solid medium, the organisms were grown at $30{ }^{\circ} \mathrm{C}$ on plates containing $\mathrm{A}$ medium (Fernández et al., 1998). For growth in liquid medium, the organisms were grown either in TSB medium (trypticase soya broth; Oxoid) or in R5A medium (Fernández et al., 1998). Streptomyces albus J1074 (ilv-1, sal-2; Kieser et al., 2000) was used as host for expression of chromomycin genes. Escherichia coli DH10B (Invitrogen) was used as a host for subcloning. E. coli ET12567 (pUB307; Kieser et al., 2000) was used as donor for intergeneric conjugation. When plasmid-containing clones were grown, the medium was supplemented with the appropriate antibiotics: 5 or $25 \mu \mathrm{g}$ thiostrepton $\mathrm{ml}^{-1}$ for liquid or solid cultures, 
respectively; $100 \mu \mathrm{g}$ ampicillin $\mathrm{ml}^{-1} ; 25 \mu \mathrm{g}$ apramycin $\mathrm{ml}^{-1} ; 20 \mu \mathrm{g}$ tobramycin $\mathrm{ml}^{-1}, \quad 25 \mu \mathrm{g}$ kanamycin $\mathrm{ml}^{-1}$; and $25 \mu \mathrm{g}$ chloramphenicol ml ${ }^{-1}$. pUC18, pHZ1358 (Kieser et al., 2000), pUK21 (Vieira \& Messing, 1991) and pIJ2925 (Kieser et al., 2000) were used for subcloning. pWHM3 (Kieser et al., 2000) and pEM4 (Quirós et al., 1998) were used for expression in S. albus. cosGR10 was used as a source of DNA (Menéndez et al., 2004a).

DNA manipulation. Plasmid DNA preparations, restriction endonuclease digestions, alkaline phosphatase treatments, DNA ligations, Southern hybridization, and other DNA manipulations, were performed according to standard techniques for E. coli (Sambrook et al., 1989) and Streptomyces (Kieser et al., 2000). Preparation of S. albus protoplasts, and transformation and selection of transformants, were carried out as described (Kieser et al., 2000). Intergeneric conjugation from E. coli ET12567 (pUB307) to S. griseus subsp. griseus was performed as described (Kieser et al., 2000). Computeraided database searching and sequence analysis were carried out using the University of Wisconsin Genetics Computer Group program package and the BLAST program.

\section{Plasmid constructs}

Several constructs (Fig. 2a) were generated in order to localize the chromomycin-resistance determinant, as described below. All the constructs were introduced by protoplast transformation into $S$. albus, and transformants were selected for thiostrepton resistance.

pNM28 ( $c m r A$ and $c m r B$ genes): a $1.9 \mathrm{~kb}$ EagI fragment containing $c m r A$ and $c m r B$, and the $3^{\prime}$ end of $c m m R I I$, was subcloned into the NotI site of pUK21; a PstI-XbaI fragment was then rescued (using these sites from the polylinker), and subcloned into the same sites of pEM4, downstream of the ermEp promoter.

pNM30 (cmmRII, cmrA and cmrB genes): a $4.6 \mathrm{~kb}$ PstI fragment from cosGR10 (one of the restriction sites derived from the vector), including $c m m R I I, c m r A, c m r B$ and the $5^{\prime}$ end of $c m r X$, was subcloned into the PstI site of pEM4; in this construct, the ermEp promoter controls expression of $\mathrm{cmmRII}, \mathrm{cmrA}$ and $\mathrm{cmrB}$.

pNM34 ( $c m r X, c m m R I I, c m r A$ and $c m r B$ genes): a $4.2 \mathrm{~kb}$ BamHI fragment containing the $5^{\prime}$ end of $c m m R I I, c m r X$ and $c m m C$ was subcloned into the same site of pUC18; this construct, pNC60A, was then digested with PstI (there is a PstI site within $c m r X$, and another in the polylinker), and a $4.6 \mathrm{~kb}$ PstI fragment from cosGR10 (one site derived from the vector), containing $c m m R I I, c m r A, c m r B$ and the $5^{\prime}$ end of $c m r X$, was inserted in the correct orientation; the whole insert in pUC18 was finally rescued as a $7.3 \mathrm{~kb}$ HindIII-EcoRI fragment (using these sites from the polylinker), and subcloned into the same sites of pWHM3, generating pNM34.

(a)
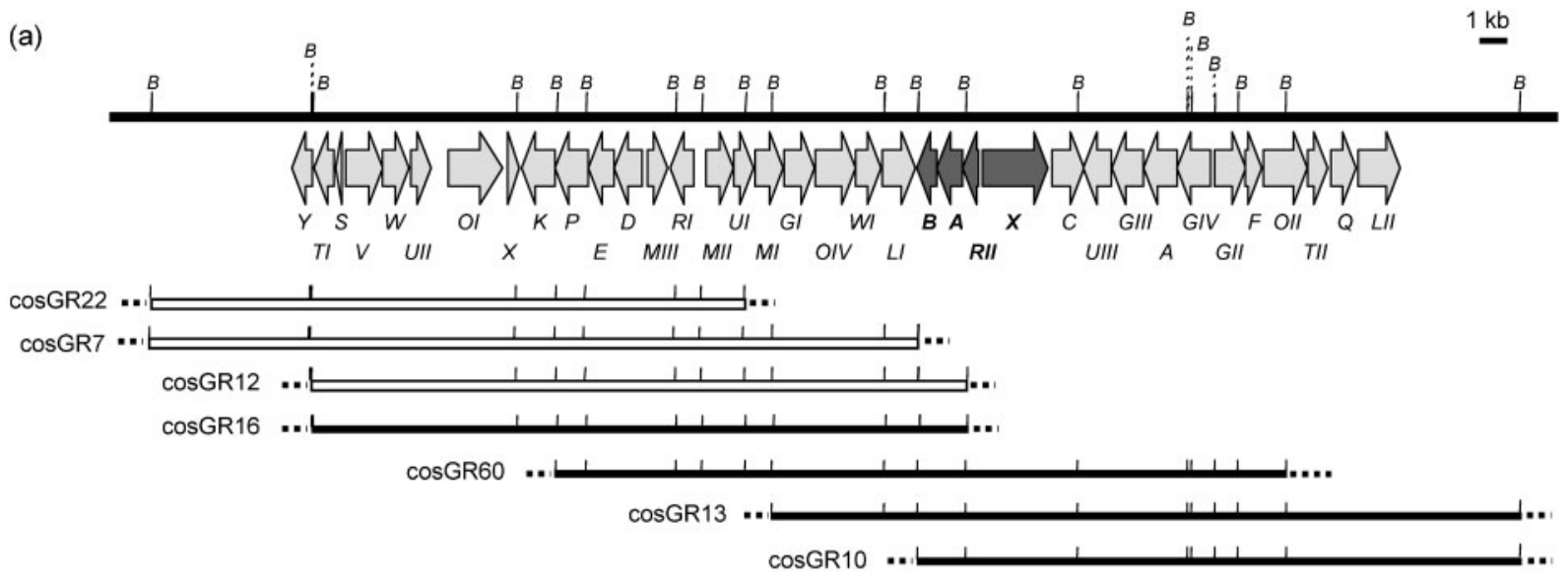

(b)

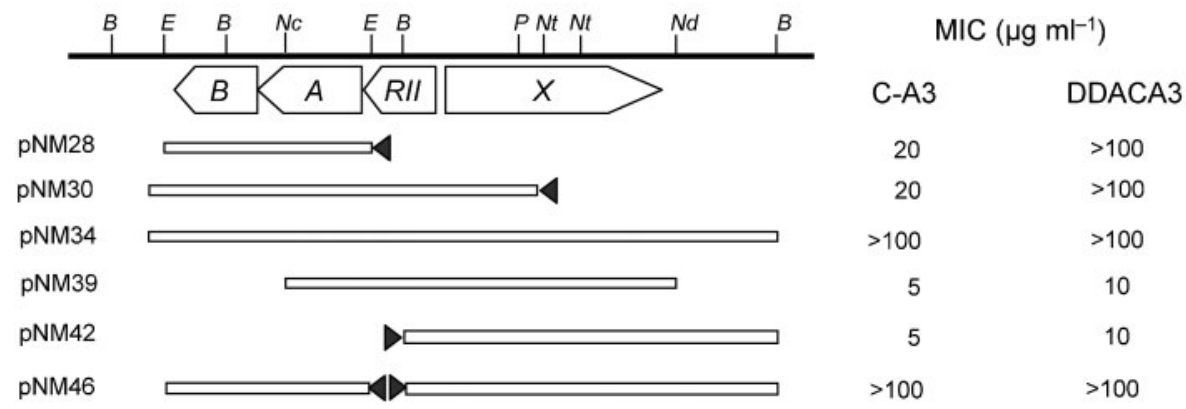

Fig. 2. (a) Genetic organization of the chromomycin biosynthesis gene cluster, and overlapping cosmids isolated from this region. Black and white bars represent cosmids conferring resistance and sensitivity to chromomycin $A_{3}$, respectively. Genes studied in this paper are in dark grey. $B, B a m H I$ sites. (b) Map of the DNA region surrounding the chromomycin-resistance genes, and constructs generated to localize the resistance determinants. MICs of chromomycin $A_{3}(C-A 3)$ and DDACA3 for $S$. albus strains expressing the different constructs are shown. Triangles indicate the position and orientation of the ermEp erythromycin-resistance promoter. B, BamHI; E, Eagl; Nc, Ncol; Nd, Ndel; Nt, Notl; P, Pstl. 
pNM39 (cmmRII and cmrX genes): a $4.2 \mathrm{~kb} N c o$-NdeI fragment, including $c m m R I I, c m r X$ and the 5' end of $c m r A$, was subcloned into the same sites of pUK21, generating pUK39; a SpeI fragment was rescued (using these sites from the polylinker), and subcloned into the XbaI site of pWHM3.

pNM42 (cmrX gene): a $4.2 \mathrm{~kb}$ BamHI fragment, containing $c m r X$ and the $5^{\prime}$ end of $c m m R I I$, was subcloned from pNC60A into the same site of pEM4, downstream of the ermEp promoter.

pNM46 ( $c m r A, c m r B$ and $c m r X$ genes): a $2.1 \mathrm{~kb}$ XbaI-HindIII (both sites blunt-ended) fragment from pNM28, containing $\mathrm{cmrA}$ and $\mathrm{cmrB}$ under the control of ermEp, was subcloned into the HindIII site (blunt-ended) of pNM42; in this construct, $c m r X$ is divergently transcribed to $c m r A$ and $c m r B$ genes.

\section{Generation of mutants}

For the generation of mutant C60RII, plasmid pC60RII was constructed as follows (Fig. 3a). A $2.65 \mathrm{~kb}$ PstI-BglII fragment (this last site was derived from the polylinker) of pUK39, containing $c m m R I I$ and the $5^{\prime}$ ends of $c m r A$ and $c m r X$, was subcloned into the PstI and BamHI sites of pUC18, generating pUR2. Then, a BamHIHindIII fragment (blunt-ended), containing an apramycin-resistance cassette, was inserted into the unique BamHI site (blunt-ended) of pUR2 located within cmmRII, and in the same direction of transcription, generating pUR2A. Afterwards, the whole insert was rescued from pUR2A as an EcoRI-HindIII fragment (using these sites from the polylinker), and subcloned into the same sites of pIJ2925, generating pJR2A. Finally, the complete insert was subcloned as a $B g l I I$ fragment (using these sites from the polylinker) into the BamHI site of pHZ1358, generating pC60RII. This construct was introduced by intergeneric conjugation into $S$. griseus, and apramycin-resistant thiostrepton-sensitive transconjugants were selected for further characterization.

For the generation of mutant C60X, plasmid pC60X was constructed as follows (Fig. 4a). pNC60A was digested with NotI, which cuts twice within $c m r X$, then treated with Klenow polymerase, and ligated to a
HindIII-BamHI fragment (blunt-ended) containing the apramycinresistance cassette, generating pXA. The whole fragment was rescued from pXA as a BamHI fragment, and subcloned into the same site of pHZ1358, generating pC60X. This construct was introduced by intergeneric conjugation into $S$. griseus, and apramycin-resistant thiostrepton-sensitive transconjugants were selected for further characterization.

Determination of antibiotic resistance. Determination of the MIC was carried out by replica plating the different strains on A medium agar plates containing different concentrations of the compounds. Susceptibility of $S$. albus recombinant strains to chromomycin $\mathrm{A}_{3}$ and DDACA3 was tested by an agar-diffusion assay. Paper disks, containing $10 \mu \mathrm{l}$ of each serially diluted compound, were put on A medium that had been seeded with spores of the strains. After incubation at $30{ }^{\circ} \mathrm{C}$ for $24 \mathrm{~h}$, the radius of the inhibitory zone was measured, and the radius of the paper disk was subtracted. Data were obtained from three independent experiments.

Determination of chromomycin $\mathbf{A}_{\mathbf{3}}$ production. Chromomycin $\mathrm{A}_{3}$ production by $S$. griseus wild-type (WT) and mutant strains was determined as follows. A seed culture was prepared in TSB medium, and inoculated with a spore suspension. After incubation for $24 \mathrm{~h}$ at $30{ }^{\circ} \mathrm{C}$ and 250 r.p.m., the culture was used to inoculate (at $2 \%$, v/v) $250 \mathrm{ml}$ flasks containing $50 \mathrm{ml} \mathrm{R} 5 \mathrm{~A}$ medium. Production of chromomycin $\mathrm{A}_{3}$ was monitored daily for 7 days, as follows: $1 \mathrm{ml}$ samples were centrifuged at 14000 r.p.m. in an Eppendorf centrifuge (model no. 5417) for $2 \mathrm{~min}$, and $200 \mu \mathrm{l}$ of the supernatant was used to test for chromomycin $\mathrm{A}_{3}$ production by using HPLC. Samples $(10 \mu \mathrm{l})$ were analysed for chromomycin $\mathrm{A}_{3}$ using a Symmetry C18 column (Waters), and isocratic elution with a mixture of $40 \%$ acetonitrile and $60 \%$ water, acidified with $0.1 \%$ TFA, at a flow rate of $1 \mathrm{ml} \mathrm{min}{ }^{-1}$. Detection and spectral characterization of peaks were performed with a photodiode array detector (Waters). Measurement of peak areas, and comparison with known concentrations of chromomycin, was used to estimate chromomycin $\mathrm{A}_{3}$ concentrations. For each experiment, two independent cultures were run and analysed. (a)

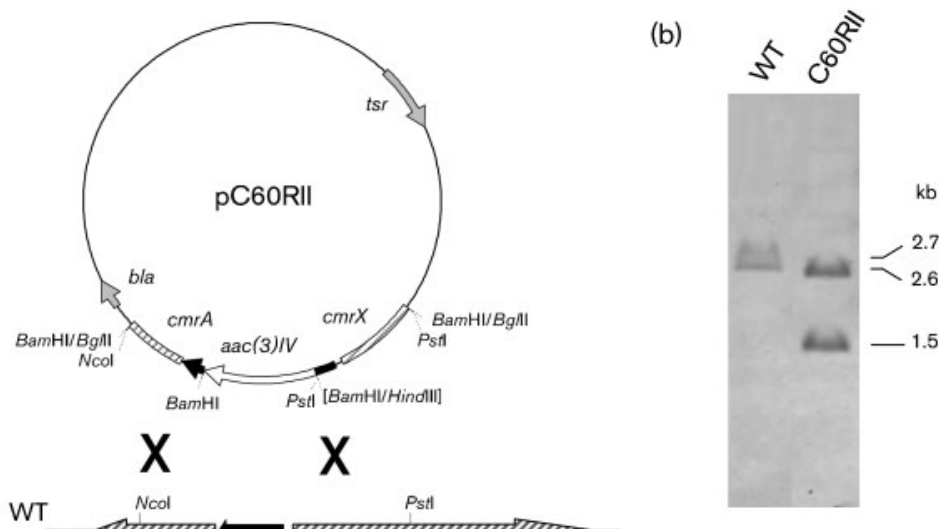

Fig. 3. Insertional inactivation of the $\mathrm{cmmR/I}$ gene. (a) Scheme representing the replacement in the chromosome of the WT cmmR/I gene with the gene mutated in vitro. aac(3)IV, apramycin-resistance gene; $t s r$, thiostreptonresistance gene; bla, ampicillin-resistance gene. (b) Southern hybridization using the $2.7 \mathrm{~kb}$ Ncol-Pstl fragment as a probe. Chromosomal DNA from the WT and the mutant C60RII was digested with $\mathrm{Ncol}$ and Pstl. 


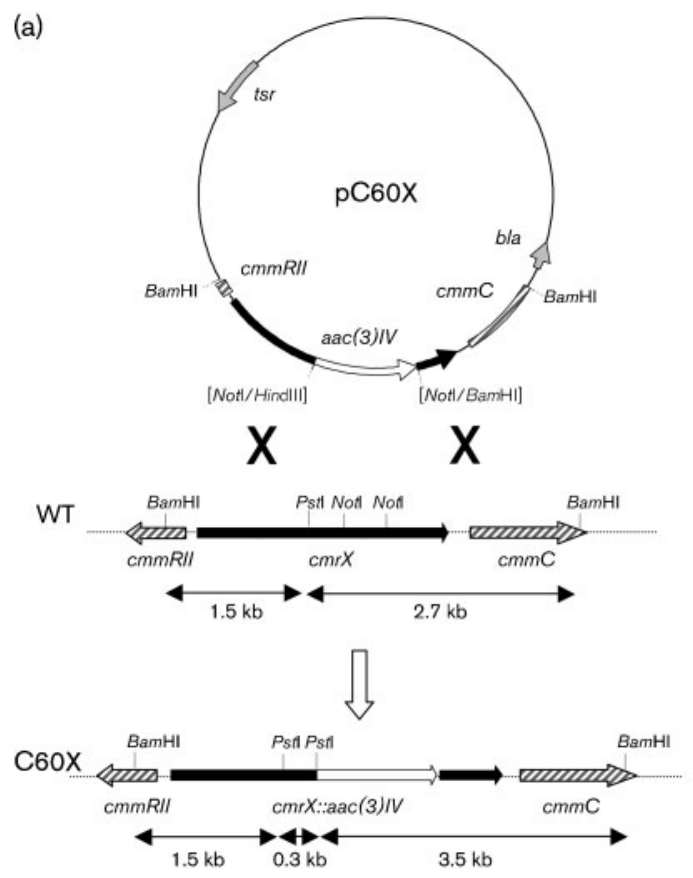

(b)

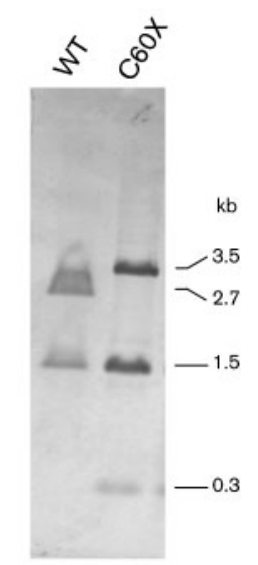

Fig. 4. Insertional inactivation of the $\mathrm{cmrX}$ gene. (a) Scheme representing the replacement in the chromosome of the WT cmrX gene with the gene mutated in vitro. aac3(IV), apramycin-resistance gene; tsr, thiostreptonresistance gene; bla, ampicillin-resistance gene. (b) Southern hybridization using the $4.2 \mathrm{~kb}$ BamHI fragment as a probe. Chromosomal DNA from the WT and the mutant C60X was digested with $\mathrm{BamHI}$ and Pstl.

\section{RESULTS}

\section{Role of the CmrAB transporter system in chromomycin $A_{3}$ resistance}

The chromomycin gene cluster of $S$. griseus contains two genes, cmrA and $c m r B$, that constitute a type I ABC transporter (Menéndez et al., 2004a). An indication of the involvement of this $\mathrm{ABC}$ transporter system in chromomycin resistance was first obtained when several cosmid constructs coming from a gene library of S. griseus, and harbouring the $\mathrm{cmrA}$ and $\mathrm{cmrB}$ genes, were expressed in the chromomycin-sensitive strain $S$. albus, rendering recombinant strains resistant to high levels of chromomycin $\mathrm{A}_{3}$ $\left(\right.$ MIC $>100 \mu \mathrm{g} \mathrm{ml}^{-1}$ ) (Fig. 2a). To confirm that the ABC transporter genes were responsible for this phenotype, we expressed the $\mathrm{cmrA}$ and $\mathrm{cmrB}$ genes, under the control of the constitutive erythromycin-resistance promoter $\mathrm{erm}^{\star} \mathrm{p}$ (pNM28) (Fig. 2b), in S. albus, and we compared the susceptibility to chromomycin $A_{3}$ of this recombinant strain (strain NM28) with that of S. albus harbouring the vector only (strain EM4). We found that the chromomycin $\mathrm{ABC}$ transporter conferred a low level of resistance to chromomycin $\mathrm{A}_{3}$ (MIC $20 \mu \mathrm{g} \mathrm{ml}^{-1}$ ) in comparison with that conferred by the vector (MIC $2.5 \mu \mathrm{g} \mathrm{ml}^{-1}$ ). These experiments indicate that the $\mathrm{ABC}$ transporter genes alone do not account for the high level of resistance shown by the chromomycin producer. Therefore, other genes must participate in self-resistance to chromomycin in S. griseus, and these could be harboured in cosmids, thus conferring a high level of resistance to chromomycin $\mathrm{A}_{3}$ to other hosts.

Strain NM28 was also tested for mithramycin resistance. Surprisingly, it was found to show a high level of resistance to mithramycin (MIC $>100 \mu \mathrm{g} \mathrm{ml}^{-1}$ ). This result was an apparent contradiction to earlier reports that have indicated that the chromomycin producer is sensitive to mithramycin, i.e. S. griseus (chromomycin producer) was unable to grow in the presence of mithramycin (Fernández et al., 1996). Since, in the present experiment, the cmrA and $c m r B$ genes were under the control of a constitutive promoter, we wondered whether the lack of resistance to mithramycin previously observed in the chromomycin producer had been due to the absence of expression of the $\mathrm{ABC}$ transporter genes in the conditions tested. We hypothesized that, perhaps, in the chromomycin producer, expression of the chromomycin-resistance genes could be induced during chromomycin production, as this has been shown to occur for other resistance determinants in producer organisms (Pernodet et al., 1993; Vilches et al., 1990). To test this hypothesis, we assayed mithramycin resistance in S. griseus after induction with low amounts of chromomycin $\mathrm{A}_{3}$. On plates inoculated with spores of $S$. griseus, $20 \mu \mathrm{g}$ chromomycin $\mathrm{A}_{3}$ was loaded onto a disc, and this was placed in the proximity of another disc containing $100 \mu \mathrm{g}$ mithramycin. The growth inhibition halo that formed around the mithramycin disc was sharply reduced in the vicinity of the chromomycin disc, suggesting a phenomenon of induction of resistance (Fig. 5). This was verified by evaluating the growth of $S$. griseus on agar plates containing $100 \mu \mathrm{g} \mathrm{ml}^{-1}$ mithramycin, with and without the addition of $2 \mu \mathrm{g} \mathrm{ml}^{-1}$ chromomycin $\mathrm{A}_{3}$ as the inducer agent: the presence of chromomycin allowed normal development of the strain on mithramycin-containing agar plates, while there was no growth in the absence of chromomycin. These experiments clearly indicate that expression of the chromomycin $\mathrm{ABC}$ transporter in the 


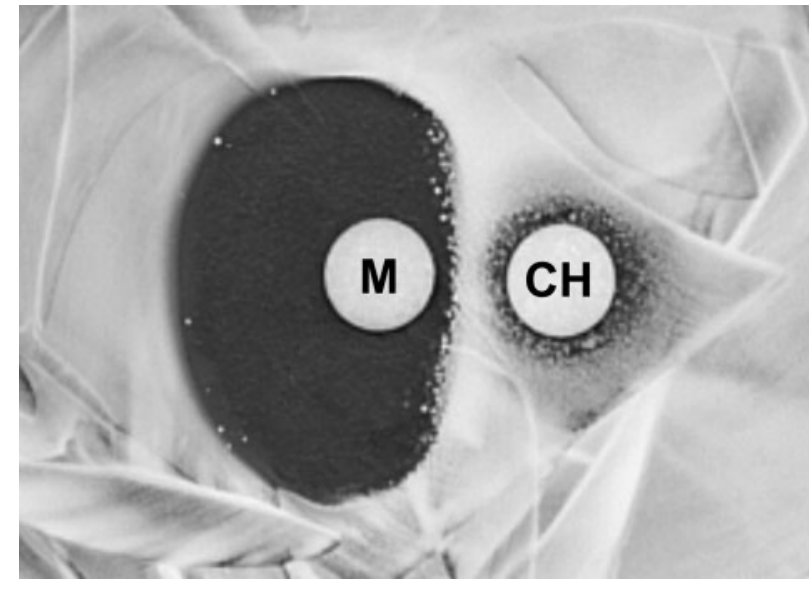

Fig. 5. Induction of mithramycin resistance in $S$. griseus subsp. griseus by chromomycin $A_{3} . C H, 20 \mu \mathrm{g}$ chromomycin $A_{3} ; M$, $100 \mu \mathrm{g}$ mithramycin.

producer organism is inducible, and that chromomycin $A_{3}$ can be used as an inducer. These results also confirm that the chromomycin $\mathrm{ABC}$ transporter confers resistance to mithramycin. In light of these results, the apparent contradiction reported above, regarding the results reported in this paper and those of Fernández et al. (1996), is not such a great contradiction, since, in those experiments, S. griseus was exposed to mithramycin before the onset of chromomycin production. Consequently, in those conditions, the $\mathrm{CmrAB}$ transporter was not expressed, and therefore S. griseus could not grow.

\section{Coexpression of the $A B C$ transporter genes with other closely linked genes}

In the chromomycin gene cluster, functions have been assigned to most of the gene products and, for many of products, these functions have been proved by insertional inactivation and analysis of the accumulated compounds (Menéndez et al., 2004a, b, 2006). Two genes of the chromomycin cluster, $c m r X$ and $c m m R I I$, were candidates to participate in chromomycin resistance based on: (i) their location in the vicinity of $c m r A$ and $c m r B$, (ii) their presence in cosmids conferring a high level of resistance to chromomycin $\mathrm{A}_{3}$, and (iii) the putative roles of the deduced gene products by database comparisons. CmrX shows high similarity to several UvrA-like proteins of $A B C$ excision nuclease systems involved in DNA repair. It also showed similarity to MtrX, which is a protein involved in mithramycin resistance in S. argillaceus (52\% identity) (Garcia-Bernardo et al., 2000), and to DrrC, which is involved in daunorubicin resistance in Streptomyces peucetius (38.2\% identity) (Lomovskaya et al., 1996). DrrC has been shown to behave like an ATP-dependent DNA-binding protein in vitro (Furuya \& Hutchinson, 1998). CmmRII showed the highest similarities to putative transcriptional regulators present in the genomes of
Nocardia farcinica (accession nos YP_118862 and YP_121769), Gloeobacter violaceus (accession no. NP_924384) and Streptomyces avermitilis (accession no. $\mathrm{BAC} 74016$ ); the similarities ranged from 23 to $31 \%$ identical amino acids, and CmmRII was shown to contain the conserved region COG1695 (predicted transcriptional regulators). CmmRII also showed similarity $(25.4 \%$ identity) to MtrY from the mithramycin cluster (Fernández et al., 1996). To test the possible requirement of one or both of these genes in conferring a high level of resistance to chromomycin $\mathrm{A}_{3}$, we subcloned a $6.8 \mathrm{~kb}$ fragment (Fig. 2b), containing the four genes $c m r B, c m r A$, cmmRII and $c m r X$, into pWHM3. When the corresponding construct (pNM34) was introduced into S. albus, the recombinant strain became highly resistant to chromomycin $A_{3}$ (MIC $>100 \mu \mathrm{g} \mathrm{ml}^{-1}$ ), indicating that high levels of resistance to chromomycin are most probably dependent on the simultaneous presence of cmmRII and/or $\mathrm{cmrX}$, together with $c m r A$ and $c m r B$. Therefore, we independently subcloned $c m r A$ and $c m r B$ genes in combination with either $c m m R I I$ (pNM30) or $c m r X$ (pNM46) (Fig. 2b). In addition, constructs with $c m r X$ alone (pNM42), or together with $\mathrm{cmmRII}$ (pNM39), were assayed (Fig. 2b). Only the construct pNM46, which harbours $c m r A, c m r B$ and $c m r X$, conferred a high level of resistance to chromomycin $A_{3}$ (MIC $>100 \mu \mathrm{g} \mathrm{ml}^{-1}$ ). Expression of the $c m r X$ gene alone conferred a very low level of resistance to chromomycin $\mathrm{A}_{3}$ $\left(\right.$ MIC $5 \mu \mathrm{g} \mathrm{ml}^{-1}$ ). These results clearly indicate that the coexpression of $c m r A, c m r B$ and $c m r X$ is required to confer a high level of resistance to chromomycin $A_{3}$. This is in contrast to what happens in the mithramycin producer, in which expression of the two genes coding for the $A B C$ transporter is sufficient to confer a high level of resistance to mithramycin (Fernández et al., 1996). These results also suggest that the chromomycin $\mathrm{ABC}$ transporter and $\mathrm{CmrX}$ could act in a cooperative way, since the level of resistance conferred by co-expression of the three genes is higher than the sum of resistance conferred by the $\mathrm{CmrAB}$ transporter or CmrX, separately.

\section{Insertional inactivation of $\mathrm{cmrX}$ and $\mathrm{cmmRI}$}

To get further information about the roles of $\mathrm{cmmRII}$ and cmrX genes in the biosynthesis and resistance to chromomycin $\mathrm{A}_{3}$, we decided to inactivate each gene in S. griseus. Using gene replacement, we generated two independent mutants, in which we replaced the WT alleles in the chromosome with the alleles that had been mutated in vitro. To do this, we generated several constructs in the unstable plasmid pHZ1358, in which each gene was interrupted by an apramycin-resistance cassette, which was inserted in the direction of transcription of the targeted gene, within the corresponding coding regions. The corresponding constructs (pC60RII for $\mathrm{cmmRII}$, and pC60X for $c m r X)$ were introduced in $S$. griseus by intergeneric conjugation, and transconjugants, in which a double crossover had taken place, were selected for their resistance to apramycin, and susceptibility to thiostrepton. 
One colony from each mutant (C60RII and C60X) was selected for further analysis. For both C60RII and C60X, it was verified by Southern hybridization that the gene replacement event had taken place (Figs 3 and 4). Both mutants were then analysed for resistance to, and production of, chromomycin $\mathrm{A}_{3}$. The C60RII mutant (cmmRII mutant), showed levels of resistance to chromomycin $A_{3}$ that were similar to those of the WT strain (Fig. 6a), but, surprisingly, the mutant was also very

(a)

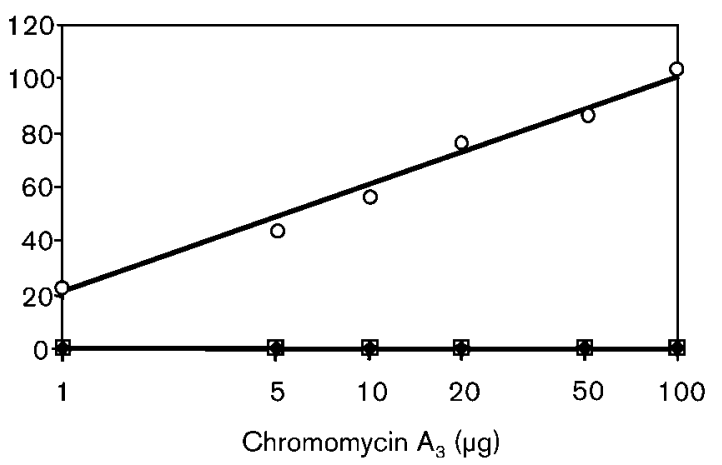

(b)

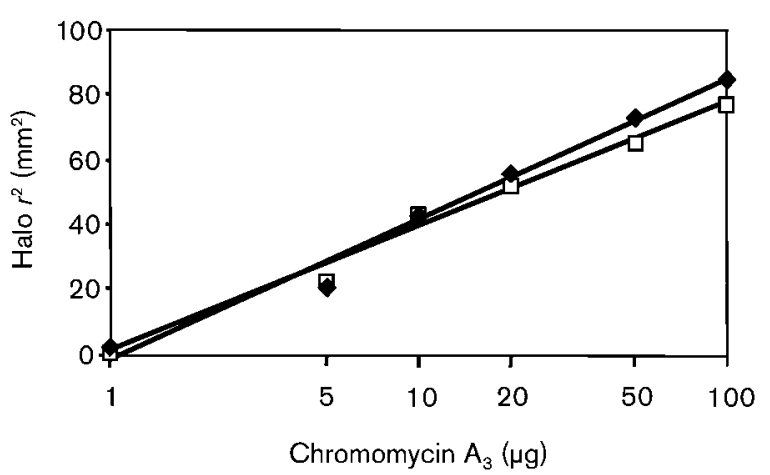

(c)

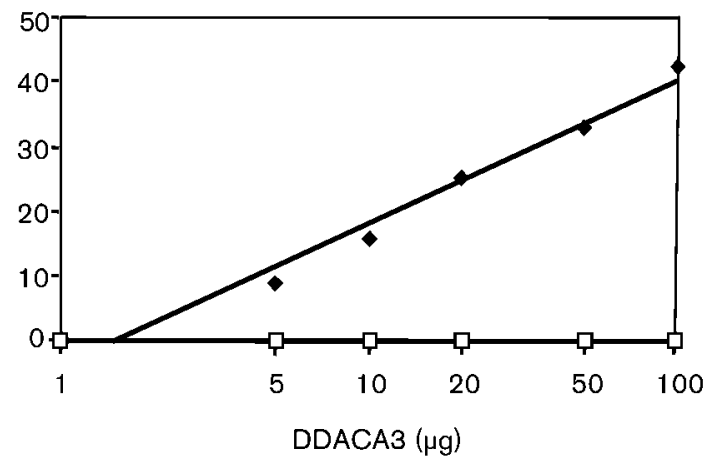

Fig. 6. (a) Susceptibility to chromomycin $A_{3}$ of $S$. griseus WT (diamond), S. griseus C60RII (square) and S. griseus C60X (circle). (b, c) Susceptibility to chromomycin $A_{3}(b)$, and DDACA3 (c), of $S$. albus EM4 control (diamond), and $S$. albus NM28 expressing $c m r A$ and $c m r B$ (square). Mean data from three independent experiments are shown (the replicate values varied by not more than $10 \%$ about the mean). resistant to mithramycin, without the addition of chromomycin $\mathrm{A}_{3}$ to the cultures as an inducer (MIC $>100 \mu \mathrm{g} \mathrm{ml}^{-1}$ ). Notably, production of chromomycin $\mathrm{A}_{3}$ in this mutant started earlier, and the yields were higher (about $70 \%$ higher), than in the case of the WT strain (Fig. 7). These results suggest that CmmRII could probably act as a transcriptional repressor in chromomycin biosynthesis/resistance. In contrast, the C60X mutant $(\mathrm{cmrX}$ mutant) was much more sensitive to chromomycin $\mathrm{A}_{3}$ than the WT strain (Fig. 6a), and it showed a reduction in chromomycin production of about $50 \%$ (Fig. 7). These results confirm that $\mathrm{CmrX}$ is implicated in chromomycin resistance, and that it is important in the self-protecting mechanism to chromomycin in S. griseus.

Insertional inactivation of the $\mathrm{ABC}$ transporter genes was also attempted. However, after three independent attempts no mutant was obtained, suggesting that inactivation of these genes is lethal for the producer strain.

\section{A chromomycin biosynthesis intermediate as a possible substrate for the $A B C$ transporter CmrAB}

As mentioned above, it was surprising that the chromomycin $\mathrm{ABC}$ transporter conferred a high level of resistance to mithramycin, but only low levels of resistance to chromomycin $\mathrm{A}_{3}$. This was not what was expected for a transporter system that it is supposed to export a highly potent antibiotic, such as chromomycin $\mathrm{A}_{3}$. We wondered if the chromomycin $\mathrm{ABC}$ transporter could recognize and secrete a biosynthesis intermediate instead of the final product chromomycin $\mathrm{A}_{3}$. It has been shown (Menéndez et al., 2004b) that the last step in chromomycin $\mathrm{A}_{3}$ biosynthesis is a sugar-tailoring modification event, consisting of the acetylation of two hydroxyl groups present in two different sugars. A single acetyltransferase $\mathrm{CmmA}$ is responsible for both of the events. By inactivating $\mathrm{cmmA}$, the biosynthesis intermediate DDACA3 (Fig. 1) was isolated. This compound lacks two acetyl groups in sugars

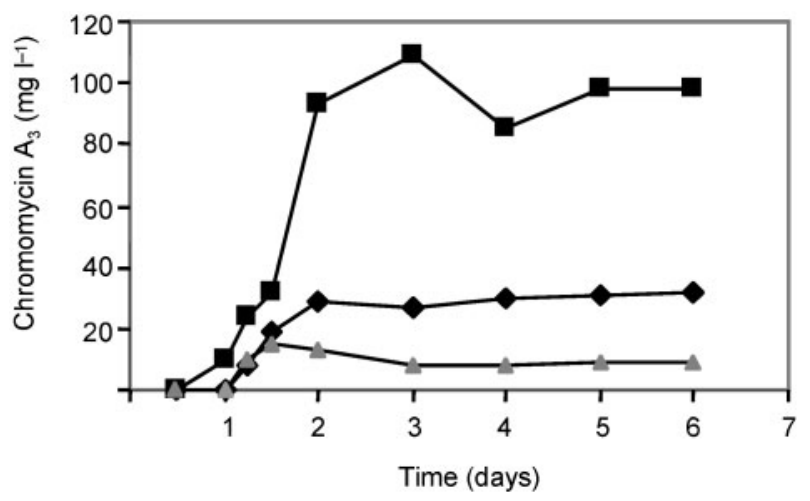

Fig. 7. Chromomycin $A_{3}$ production by $S$. griseus WT (diamond), and mutant strains C60RII (square) and C60X (triangle). Mean data from two independent experiments are shown. 
A and E, and shows antibiotic activity, although its activity is lower than that in the final compound. Since DDACA3 is the immediate precursor of chromomycin $\mathrm{A}_{3}$, and based on the fact that $\mathrm{CmmA}$ acetyltransferase is a membrane protein (B. García, N. Menéndez, J. A. Salas \& C. Méndez, unpublished), we hypothesized that perhaps DDACA3 could be the actual substrate for the $\mathrm{CmrAB} A B C$ transporter. If this was the case, the $\mathrm{CmrAB}$ transporter should confer resistance to this compound. Consequently, we tested the susceptibility of $S$. albus recombinant strain NM28 (expressing $c m r A$ and $c m r B$ ) to the dideacetylated intermediate, and compared the results with those for chromomycin $\mathrm{A}_{3}$ (Fig. 6). As shown in Fig. 6, S. albus NM28 was highly sensitive to chromomycin $A_{3}$ (Fig. 6b), but highly resistant to DDACA3 (Fig. 6c). However, the control strain ( $S$. albus EM4) was sensitive to both chromomycin $\mathrm{A}_{3}$ and DDACA3. In addition, we also tested the DDACA3 susceptibility of other $S$. albus recombinant strains expressing different combinations of $c m r$ genes (Fig. 2b). Only those strains expressing $c m r A$ and $c m r B$ were highly resistant to DDACA3. These results indicate that the $\mathrm{CmrAB} A B C$ transporter efficiently secretes DDACA3, but not chromomycin $\mathrm{A}_{3}$. On the other hand, strains expressing $c m r X$, but not $c m r A B$, showed a low level of resistance to DDACA3, suggesting that $\mathrm{CmrX}$ could play a role in $S$. griseus in self-protection against bioactive intermediates, such as DDACA3, synthesized during the biosynthesis of chromomycin $\mathrm{A}_{3}$. In agreement with this, analysis of the susceptibility of $S$. griseus C60X (cmrX mutant) to DDACA3 showed that, although no inhibition of growth was observed at short incubation times, there was reduced growth over longer time periods. This effect was not observed with either the WT strain or the mutant C60RII, as both showed normal growth (data not shown).

\section{DISCUSSION}

Antibiotic-producing micro-organisms protect themselves from the inhibitory/lethal action of antibiotics they produce by developing self-protection mechanisms (Cundliffe, 1989; Martin et al., 2005; Méndez \& Salas, 2001). The chromomycin producer S. griseus subsp. griseus is highly resistant to chromomycin $A_{3}$, and the chromomycin gene cluster contains three genes ( $c m r A, c m r B$ and $c m r X$ ) that are involved in self-resistance to chromomycin $\mathrm{A}_{3}$. Genes $c m r A$ and $c m r B$ encode for an $A B C$ transporter system, which is an efflux mechanism for the drug, and $c m r X$ encodes a UvrA-like protein of $\mathrm{ABC}$ excision nuclease systems, which are responsible for DNA repair. Confirmation of the role of these genes in chromomycin resistance was achieved by independently or jointly expressing these genes in the chromomycin-sensitive strain $S$. albus. The results indicated that expression of the three genes $(c m r A, c m r B$ and $c m r X)$ was required to confer a high level of resistance to chromomycin $\mathrm{A}_{3}$. Expression of either $c m r A$ and $c m r B$, or $c m r X$, resulted in a low level of resistance to chromomycin $\mathrm{A}_{3}$. Consequently, $c m r A B$ and $c m r X$ are two chromomycin-resistance determinants. Additional confirmation of the essential role of $\mathrm{cmrX}$ in self-resistance to chromomycin $\mathrm{A}_{3}$ was achieved by insertional inactivation of this gene; this resulted in the generation of a strain that was more sensitive to, and produced less of, chromomycin $A_{3}$. In a similar way, we tried to inactivate $c m r A B$, but this was not achieved, and it suggests that mutations in these genes are lethal for the producer strain. A similar situation occurs in the mithramycin producer, in which the inactivation of the mithramycin $\mathrm{ABC}$ transporter was also pursued, but not achieved, in the producer strain (Fernández et al., 1998). On the basis of these results, we speculate that CmrX could be a DNA-binding protein that plays a role in self-resistance to chromomycin by inhibiting or destabilizing the interaction of chromomycin $\mathrm{A}_{3}$ (and precursors) and genomic DNA, thus preventing chromomycin from interfering with cell transcription and/or replication. A similar mechanism has also been proposed for the analogous protein DrrC, which is another UvrA-like protein from the daunorubicin gene cluster that has been shown to behave in vitro like an ATP-dependent DNAbinding protein (Furuya \& Hutchinson, 1998; Lomovskaya et al., 1996). In addition, CmrX could play a regulatory role in chromomycin biosynthesis, since its absence leads to lower production yields of chromomycin. In relation to this, it has been shown that the CmrX-like protein DrrC can bind the promoter region of the regulatory gene $d n r I$, which is involved in daunorubicin biosynthesis (Furuya \& Hutchinson, 1998). In the case of chromomycin biosynthesis, one can speculate that, in the absence of $\mathrm{CmrX}$, the expression of regulatory genes could be affected.

The chromomycin-resistance genes are grouped in the chromosome, together with a gene encoding a transcriptional repressor $(\mathrm{cmmRII})$, which most probably plays a role as a transcriptional repressor in chromomycin resistance/biosynthesis in the producer organism. Thus, its inactivation makes $S$. griseus a high producer of chromomycin $\mathrm{A}_{3}$, and a strain constitutively resistant to mithramycin. However, its presence is not essential to confer resistance to chromomycin $\mathrm{A}_{3}$ in a heterologous host if the chromomycin-resistance genes are expressed under the control of a constitutive promoter, i.e. the ermEp promoter.

The chromomycin $\mathrm{ABC}$ transporter appears to play a major role in the self-protection system of $S$. griseus, since its disruption seems to be lethal to the micro-organism, and its expression in S. albus resulted in a higher level of resistance compared with the expression of $\mathrm{cmrX}$. ABC transporters are frequently found in antibiotic-biosynthesis gene clusters, where they play a role in secreting the antibiotic out of the cell, thus preventing the antibiotic from acting on internal cell structures or enzymes (Fernández et al., 1996; Guilfoile \& Hutchinson, 1991; Olano et al., 1995). Surprisingly, the CmrAB transporter confers a low level of resistance to chromomycin $\mathrm{A}_{3}$, but it 
confers a high level of resistance to the biosynthesis intermediate DDACA3; this indicates that this biosynthesis intermediate is the substrate for the $\mathrm{CmrAB}$ transporter. Conversion of this compound into chromomycin $\mathrm{A}_{3}$ is carried out by the action of the acetyltransferase $\mathrm{CmmA}$ (Menéndez et al., 2004b), which has been shown recently to be a transmembrane protein (B. García, N. Menéndez, J. A. Salas \& C. Méndez, unpublished). Taking all these findings into account, we propose a model for the biosynthesis of, and self-resistance to, chromomycin $\mathrm{A}_{3}$ in S. griseus subsp. griseus, by which chromomycin biosynthesis proceeds through intermediates with weak biological activity. CmrX participates in protecting the producer against these compounds that have low bioactivity. The last intracellular product is the dideacetylated, but methylated, intermediate DDACA3. This compound, which also shows weaker antibiotic activity, is recognized by the $\mathrm{ABC}$ transporter $\mathrm{CmrAB}$, and then acetylated by the membrane-bound $\mathrm{CmmA}$, and thus converted into the fully biologically active chromomycin $A_{3}$. This model of biosynthesis represents an evolutionary advantage for the producer strain to survive during antibiotic biosynthesis, since formation of the antibiotic is not completed inside the cell, but requires a final step. In this way, the organism avoids the interaction of the harmful compound chromomycin $\mathrm{A}_{3}$ with its intracellular target. In some macrolide producers, such as Streptomyces antibioticus (oleandomycin producer) and Streptomyces venezuelae (methymycin producer), the active compounds are not found inside the cell; however, in these micro-organisms, the situation is rather different to the chromomycin producer, since the biosynthesis of the antibiotics is actually completed inside the cell, but the antibiotics are modified by glycosylation to render them inactive, and they are then activated once they are outside the cell (Quirós et al., 1998; Zhao et al., 2003). In contrast, in the chromomycin producer, formation of the fully active compound requires the incorporation of additional functional groups (i.e. acetyl groups) to DDACA3, and this probably occurs during the secretion process. Studies now in progress are focused on determining the affinity of the $\mathrm{ABC}$ transporter by the deacetylated intermediate, and on elucidating the possible interaction between the $\mathrm{ABC}$ transporter and the acetyltransferase CmmA.

\section{ACKNOWLEDGEMENTS}

This work was supported by grants from the Spanish Ministry of Education and Science to C.M. (BMC2002-03599 and BIO200504115), and a grant from the Plan Regional de Investigación del Principado de Asturias to J.A.S. (GE-MEDO1-05). N.M. was the recipient of a predoctoral fellowship of the FICYT. We wish to thank C. Olano for helpful discussion.

\section{REFERENCES}

Barcelo, F., Scotta, C., Ortiz-Lombardia, M., Mendez, C., Salas, J. A. \& Portugal, J. (2007). Entropically driven binding of mithramycin in the minor groove of C/G-rich DNA sequences. Nucleic Acids Res 35, 2215-2226.

Bianchi, N., Rutigliano, C., Passadore, M., Tomassetti, M., Pippo, L., Mischiati, C., Feriotto, G. \& Gambari, R. (1997). Targeting of the HIV-1 long terminal repeat with chromomycin potentiates the inhibitory effects of a triplex-forming oligonucleotide on Sp1-DNA interactions and in vitro transcription. Biochem J 326, 919-927.

Bianchi, N., Osti, F., Rutigliano, C., Corradini, F. G., Borsetti, E., Tomassetti, M., Mischiati, C., Feriotto, G. \& Gambari, R. (1999). The DNA-binding drugs mithramycin and chromomycin are powerful inducers of erythroid differentiation of human K562 cells. $\mathrm{Br} \mathrm{J}$ Haematol 104, 258-265.

Blanco, G., Fu, H., Mendez, C., Khosla, C. \& Salas, J. A. (1996). Deciphering the biosynthetic origin of the aglycone of the aureolic acid group of anti-tumor agents. Chem Biol 3, 193-196.

Blanco, G., Fernández, E., Fernández, M. J., Braña, A. F., Weißbach, U., Künzel, E., Rohr, J., Méndez, C. \& Salas, J. A. (2000). Characterization of two glycosyltransferases involved in early glycosylation steps during biosynthesis of the antitumor polyketide mithramycin by Streptomyces argillaceus. Mol Gen Genet 262, 991-1000.

Chatterjee, S., Zaman, K., Ryu, H., Conforto, A. \& Ratan, R. R. (2001). Sequence-selective DNA binding drugs mithramycin A and chromomycin $A_{3}$ are potent inhibitors of neuronal apoptosis induced by oxidative stress and DNA damage in cortical neurons. Ann Neurol 49, 345-354.

Cundliffe, E. (1989). How antibiotic-producing organisms avoid suicide. Annu Rev Microbiol 43, 207-233.

Fernández, E., Lombó, F., Méndez, C. \& Salas, J. A. (1996). An ABC transporter is essential for resistance to the antitumor agent mithramycin in the producer Streptomyces argillaceus. Mol Gen Genet 251, 692-698.

Fernández, E., Weibbach, U., Sánchez Reillo, C., Braña, A. F., Méndez, C., Rohr, J. \& Salas, J. A. (1998). Identification of two genes from Streptomyces argillaceus encoding two glycosyltransferases involved in the transfer of a disaccharide during the biosynthesis of the antitumor drug mithramycin. J Bacteriol 180, 4929-4937.

Furuya, K. \& Hutchinson, C. R. (1998). The DrrC protein of Streptomyces peucetius, a UvrA-like protein, is a DNA-binding protein whose gene is induced by daunorubicin. FEMS Microbiol Lett 168, 243-249.

Garcia-Bernardo, J., Braña, A. F., Mendez, C. \& Salas, J. A. (2000). Insertional inactivation of $m t r X$ and $m t r Y$ genes from the mithramycin gene cluster affects production and growth of the producer organism Streptomyces argillaceus. FEMS Microbiol Lett 186, 61-65.

González, A., Remsing, L. L., Lombó, F., Fernández-Lozano, M. J., Prado, L., Braña, A. F., Rohr, J., Méndez, C. \& Salas, J. A. (2001). The $m t m C U V$ genes of the antitumor mithramycin gene cluster are involved in the biosynthesis of the sugar moieties. Mol Gen Genet 264, 827-835.

Guilfoile, P. G. \& Hutchinson, C. R. (1991). A bacterial analog of the $m d r$ gene of mammalian tumor cells is present in Streptomyces peucetius, the producer of daunorubicin and doxorubicin. Proc Natl Acad Sci U S A 88, 8553-8557.

Kieser, T., Bibb, M. J., Buttner, M. J., Chater, K. F. \& Hopwood, D. A. (2000). Practical Streptomyces Genetics. Norwich, UK: The John Innes Foundation.

Lombó, F., Blanco, G., Fernández, E., Méndez, C. \& Salas, J. A. (1996). Characterization of Streptomyces argillaceus genes encoding a polyketide synthase involved in the biosynthesis of the antitumor mithramycin. Gene 172, 87-91.

Lombó, F., Siems, K., Braña, A. F., Méndez, C., Bindseil, K. \& Salas, J. A. (1997). Cloning and insertional inactivation of Streptomyces 
argillaceus genes involved in earliest steps of sugar biosynthesis of the antitumor polyketide mithramycin. J Bacteriol 179, 3354-3357.

Lomovskaya, N., Hong, S. K., Kim, S. U., Fonstein, L., Furuya, K. \& Hutchinson, C. R. (1996). The Streptomyces peucetius $d r r C$ gene encodes a UvrA-like protein involved in daunorubicin resistance and production. J Bacteriol 178, 3238-3245.

Lozano, M. J., Remsing, L. L., Quirós, L. M., Braña, A. F., Fernández, E., Sánchez, C., Méndez, C., Rohr, J. \& Salas, J. A. (2000). Characterization of two polyketide methyltransferases involved in the biosynthesis of the antitumor drug mithramycin by Streptomyces argillaceus. J Biol Chem 275, 3065-3074.

Martin, J. F., Casqueiro, J. \& Liras, P. (2005). Secretion systems for secondary metabolites: how producer cells send out messages of intercellular communication. Curr Opin Microbiol 8, 282-293.

Méndez, C. \& Salas, J. A. (2001). The role of ABC transporters in antibiotic-producing organisms: drug secretion and resistance mechanism. Res Microbiol 152, 341-350.

Menéndez, N., Mohammad, N., Braña, A. F., Rohr, J., Salas, J. A. \& Méndez, C. (2004a). Biosynthesis of the antitumor chromomycin $\mathrm{A}_{3}$ in Streptomyces griseus: analysis of the gene cluster and rational design of novel chromomycin analogues. Chem Biol 11, 21-32.

Menéndez, N., Nur-e-Alam, M., Braña, A. F., Rohr, J., Salas, J. A. \& Méndez, C. (2004b). Tailoring modification of deoxysugars during biosynthesis of the antitumor drug chromomycin $\mathrm{A}_{3}$ by Streptomyces griseus subsp. griseus. Mol Microbiol 53, 903-915.

Menéndez, N., Nur-e-Alam, M., Fischer, C., Braña, A. F., Salas, J. A., Rohr, J. \& Méndez, C. (2006). Deoxysugar transfer during chromomycin $\mathrm{A}_{3}$ biosynthesis in Streptomyces griseus subsp. griseus: new derivatives with antitumor activity. Appl Environ Microbiol 72, 167-177.

Olano, C., Rodríguez, A. M., Méndez, C. \& Salas, J. A. (1995). A second $\mathrm{ABC}$ transporter is involved in oleandomycin resistance and its secretion by Streptomyces antibioticus. Mol Microbiol 16, 333-343.

Pernodet, J. L., Alegre, M. T., Blondelet-Rouault, M. H. \& Guerineau, M. (1993). Resistance to spiramycin in Streptomyces ambofaciens, the producer organism, involves at least two different mechanisms. J Gen Microbiol 139, 1003-1011.

Prado, L., Lombó, F., Braña, A. F., Méndez, C., Rohr, J. \& Salas, J. A. (1999). Analysis of two chromosomal regions adjacent to a type II polyketide synthase involved in the biosynthesis of the antitumor polyketide mithramycin in Streptomyces argillaceus. Mol Gen Genet 261, 216-225.

Quirós, L. M., Aguirrezabalaga, I., Olano, C., Méndez, C. \& Salas, J. A. (1998). Two glycosyltransferases and a glycosidase are involved in oleandomycin modification during its biosynthesis by Streptomyces antibioticus. Mol Microbiol 28, 1177-1186.

Remers, W. A. (1979). The Chemistry of Antitumor Antibiotics, vol. 1, pp. 133-175. New York: Wiley Interscience.

Rohr, J., Méndez, C. \& Salas, J. A. (1999). The biosynthesis of aureolic acid group antibiotics. Bioorg Chem 27, 41-54.

Sambrook, J., Fritsch, E. F. \& Maniatis, T. (1989). Molecular Cloning: a Laboratory Manual. Cold Spring Harbor, NY: Cold Spring Harbor Laboratory.

Sastry, M. \& Patel, D. J. (1993). Solution structure of the mithramycin dimer-DNA complex. Biochemistry 32, 6588-6604.

Sastry, M., Fiala, R. \& Patel, D. J. (1995). Solution structure of mithramycin dimers bound to partially overlapping sites on DNA. J Mol Biol 251, 674-689.

Skarbek, J. D. \& Speedie, M. K. (1981). Antitumor Compounds of Natural Origin, vol. 1, pp. 191-235. Edited by A. Aszalos. Boca Raton, FL: CRC Press.

Vieira, J. \& Messing, J. (1991). New pUC-derived cloning vectors with different selectable markers and DNA replication origins. Gene 100, 189-194.

Vilches, C., Méndez, C., Hardisson, C. \& Salas, J. A. (1990). Biosynthesis of oleandomycin by Streptomyces antibioticus: influence of nutritional conditions and development of resistance. J Gen Microbiol 136, 1447-1454.

Wohlert, S. E., Kunzel, E., Machinek, R., Mendez, C., Salas, J. A. \& Rohr, J. (1999). The structure of mithramycin reinvestigated. J Nat Prod 62, 119-121.

Zhao, L., Beyer, N. J., Borisova, S. A. \& Liu, H. W. (2003). $\beta$ Glucosylation as a part of self-resistance mechanism in methymycin/ pikromycin producing strain Streptomyces venezuelae. Biochemistry 42, 14794-14804.

Edited by: J. Anné 